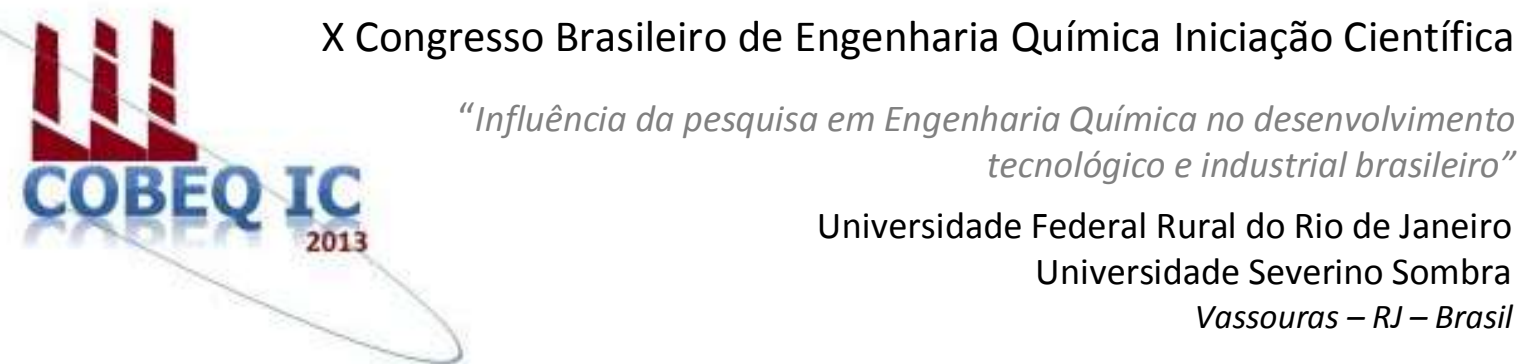

\title{
CARACTERIZAÇÃO E TRATAMENTO DO EFLUENTE ORIUNDO DE LAVAGENS AUTOMOTIVAS DO MUNICÍPIO DE BAGÉ-RS
}

\author{
ALTHAUS, M. ${ }^{1}$; ROSA G. S. ${ }^{2}$ \\ ${ }^{1}$ Discente EQ/UNIPAMPA ${ }^{2}$ Docente EQ/UNIPAMPA \\ Engenharia Química - Campus Bagé - Universidade Federal do Pampa \\ Travessa 45, $n^{\circ} .1650$ - Bagé, RS - CEP 96413-170 \\ e-mail: gabrielarosa@unipampa.edu.br
}

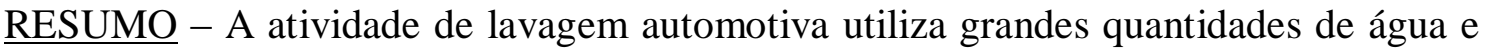
gera efluentes potencialmente poluidores. A proposta deste trabalho é a caracterização deste efluente e a concepção de uma metodologia para o tratamento do mesmo. As amostras foram caracterizadas para os seguintes parâmetros: $\mathrm{pH}$, turbidez, óleos e graxas, $\mathrm{DBO}_{5}, \mathrm{ST}, \mathrm{SFT}$ e SVT. No tratamento do efluente utilizou-se $20 \mathrm{mg} / \mathrm{L}$ do cloreto férrico, com $1 \mathrm{~min}$ de coagulação, $10 \mathrm{~min}$ de floculação e $15 \mathrm{~min}$ de sedimentação. Constatou-se que o efluente após o tratamento proposto permaneceu fora dos padrões estabelecidos pela resolução $n^{0} 430$ do CONAMA de 2011 para alguns parâmetros, sendo estes: $\mathrm{DBO}_{5}$ que apresentou uma redução de apenas $32 \%$, óleos e graxas de $37,4 \pm 6 \mathrm{mg} / \mathrm{L}$. A partir do tratamento proposto neste trabalho não se obteve um efluente com todos os parâmetros em conformidade com o exigido pela legislação, porém, conseguiu-se uma diminuição da carga poluidora. Com base nos resultados obtidos sugeriu-se uma adaptação do sistema utilizado atualmente nas lavagem automotivas.
\end{abstract}

Palavras chave: coagulação, floculação, sedimentação.

\section{INTRODUÇÃO}

Nos últimos anos a frota de veículos aumentou e com isso alguns serviços também aumentaram como, por exemplo, as lavagens de veículos. De acordo com dados do DENATRAN (2013), antes de 2000 o Brasil apresentava uma frota de veículos de 24 milhões. Atualmente existe mais de 79 milhões de veículos fabricados no Brasil, isso faz com que os processos de manutenção, incluindo a lavagem de veículos, aumentem, provocando impactos ambientais negativos. No município de Bagé-RS, até o mês de julho de 2013 estavam registrados 56.046 veículos.

A instalação e o funcionamento da lavagem de veículos são atividades que causam impactos negativos ao meio ambiente, portanto requerem o licenciamento ambiental, que deve estar em conformidade com a lei $\mathrm{n}^{\circ}$ 6.938, de 31 de agosto de 1981. Com relação ao lançamento dos efluentes gerados por esses estabelecimentos deve-se cumprir as determinações da resolução número 430 de 
2011 do CONAMA, devendo-se também observar a resolução número 128 de 2006 do CONSEMA, que dispõem sobre os padrões e as condições de lançamento dos efluentes.

Como esquematizado na Figura 1, o tratamento utilizado pelas lavagens de veículos atualmente é um gradeamento nas entradas das canaletas (1) para reter os sólidos maiores. Após, o efluente é encaminhado para caixa de retenção (2), onde o material sólido (lodo) decanta e fica retido no fundo, esta caixa deve ter dimensões que proporcionem velocidade baixa de fluxo. O lodo proveniente desta caixa está contaminado, consequentemente necessita ser destinado para uma empresa que possa dar o destino correto para o mesmo. A partir desse momento teoricamente o efluente não apresenta mais matéria orgânica considerável, apenas uma mistura de água e óleo, a qual é transferida para o separador água e óleo (3), que por diferença entre as massas específicas realiza a separação. O óleo por apresentar menor massa específica que a água permanece na superfície, e isso faz com que o mesmo seja desviado para outra caixa (4), onde é recolhido e encaminhado para empresa que possa dar o destino final correto para o mesmo. Por fim, a água resultante pode ser encaminhada para a rede de esgotos (5).

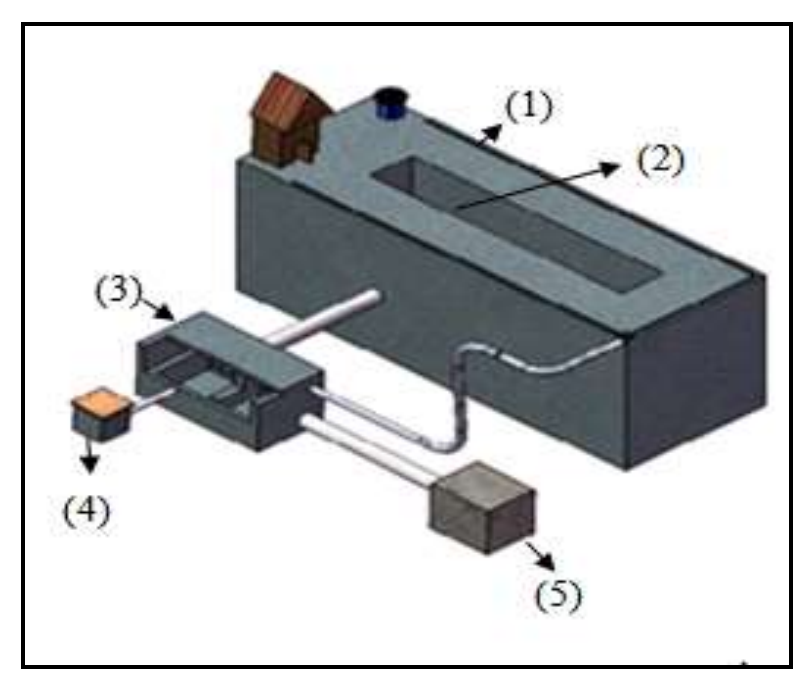

Figura 1 - Tratamento utilizado pelas lavagens de veículos atualmente.

Entre as técnicas de tratamento de efluentes usualmente uttilizadas tem-se a coagulação, floculação e sedimentação. A coagulação tem como objetivo fundamental aglomerar as impurezas que se encontram em suspensões finas (estado coloidal) ou algumas vezes dissolvidas em partículas maiores que possam ser removidas por decantação ou filtração. Entre os diversos fatores que influenciam a coagulação se encontram a espécie de coagulante e a quantidade de coagulante (Dezotti, 2008).

$\mathrm{Na}$ coagulação com a utilização de sais de ferro a formação de flocos é mais rápido, devido ao alto peso molecular comparado ao alumínio, consecutivamente os flocos são mais densos, e o tempo de sedimentação é reduzido significativamente. Comparado com sulfatos, os cloretos férricos têm baixo consumo de alcalinidade, e, consequentemente, menor redução de $\mathrm{pH}$ (Pavanelli, 2001).

Subsequente à etapa de coagulação, ocorre à floculação que é a aglomeração dos coloides descarregados, até a formação de flocos que sedimentam a uma velocidade adequada. Esta etapa é favorecida pela agitação suave, que facilita o contato dos coágulos uns com os outros e evita a quebra dos flocos formados. Depois das estapas de coagulação e floculação ocorre a sedimentação (ou decantação) que é uma operação unitária para a separação sólido-líquido e se baseia na diferença de densidade entre as fases, é muito empregada para remoção de sólidos em suspensão não retidos pelas grades ou peneiras (Dezotti, 2008).

O desenvolvimento deste trabalho justifica-se devido ao grande número de postos de lavagem de veículos existentes no município de Bagé-RS, e pela quantidade de água utilizada para cada lavagem. Além disso, a cidade sofre com restrição do consumo de água há décadas, e desta forma a busca por alternativas relacionadas ao assunto torna-se relevante.

Este trabalho teve como objetivo a caracterização do efluente proveniente das lavagens automotivas e a proposta de uma metodologia para o tratamento do mesmo.

\section{MATERIAIS E MÉTODOS}

\section{Escolha Do Local Da Coleta Das Amostras}

Depois de analisar os quinze estabelecimentos visitados no município de Bagé-RS, escolheu-se o que melhor estava em conformidade com a norma ABNT NBR14.605, ou seja, possuía chão 
impermeabilizado, canaletas, caixa de retenção do lodo (sendo esse lodo retirado todas as segundas-feiras) e caixa de separação água e óleo. Além disso, este estabelecimento apresentava licença de operação, alvará, licença dos bombeiros, comprovantes do encaminhamento do lodo para empresa terceirizada, e mostrou-se preocupado com a situação ambiental, disponibilizando as amostras para o desenvolvimento deste trabalho. Nesse estabelecimento os veículos são lavados manualmente com uma mangueira com jato de alta pressão

\section{Matéria prima}

O local de coleta das amostras do efluente bruto foi no box de lavagem, pois neste ponto consegue-se garantir a presença dos constituintes do efluente gerado pela lavagem do veículo.

\section{Análises Físico-Químicas}

As amostras foram caracterizadas para os seguintes parâmetros: $\mathrm{pH}$ através de medidor de $\mathrm{pH}$ digital de bancada, turbidez através de turbidímetro digital, óleos e graxas pelo método de extração Soxhlet, $\mathrm{DBO}_{5}$ pelo consumo de oxigênio que um volume padronizado do efluente exerce em um período de cinco dias a temperatura de incubação de 20 ${ }^{\circ} \mathrm{C}$. A determinação dos sólidos totais foi realizada por evaporação do efluente a 103$105{ }^{\circ} \mathrm{C}$ em estufa por $24 \mathrm{~h}$, enquanto que os sólidos totais fixos foram determinados em forno mufla a $600{ }^{\circ} \mathrm{C}$ e os sólidos totais voláteis pela diferença destes.

Esta caracterização físico-química foi efetuada antes e após o tratamento proposto. Estas análises foram realizadas de acordo com as metodologias expostas pela CETESB (SILVA, 1977) e em triplicatas para garantir a reprodutibilidade dos resultados (em sua maioria).

\section{Procedimento Experimental}

Para os ensaios de tratamento do efluente proveniente da lavagem automotiva empregou-se as técnicas de coagulação e floculação seguidas pela etapa de sedimentação. Esse experimento foi realizado em escala de bancada utilizando o equipamento jar-test, da marca ECO Engenharia, exposto na Figura 2.

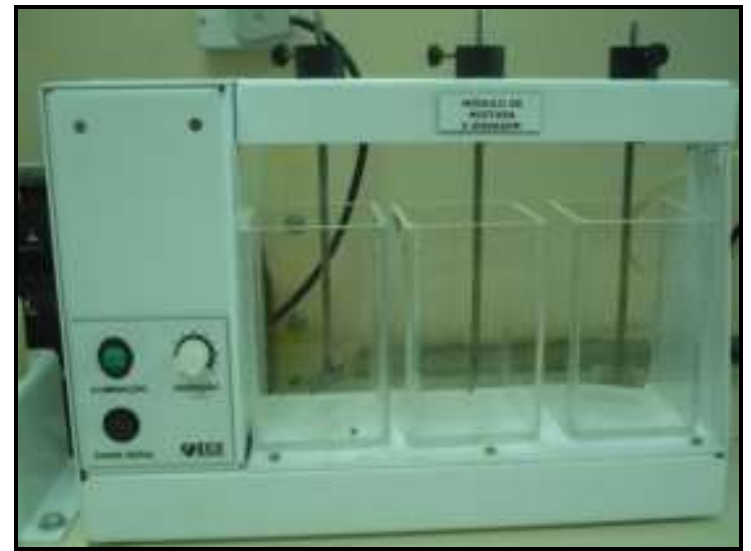

Figura 2 - Equipamento de jar-test.

Foram realizados testes preliminares para verificar a dosagem de cloreto férrico e tempos para os diferentes procedimentos. Para o tratamento do efluente utilizou-se $20 \mathrm{mg} / \mathrm{L}$ do cloreto férrico, com $1 \mathrm{~min}$ de coagulação, $10 \mathrm{~min}$ de floculação e $15 \mathrm{~min}$ de sedimentação.

\section{RESULTADOS E DISCUSSÃO}

$\mathrm{O}$ efluente no início do tratamento proposto, apresentado na Figura 3(a), possuía coloração escura, odor desagradável e cheiro intenso de óleo.

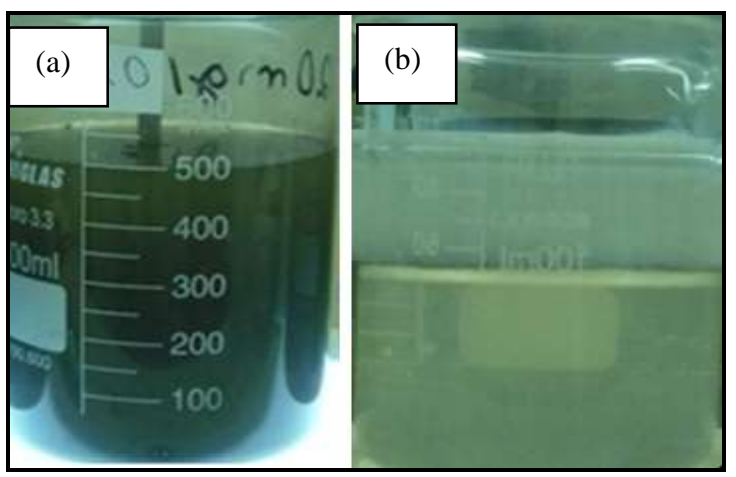

Figura 3 - Efluente: (a) no início do tratamento proposto e (b) sobrenadante retirado após o tratamento.

Observa-se na Figura3 (b), que o efluente após o ensaio de coagulação/floculação e sedimentação tornouse muito menos turvo que o efluente bruto, exposto na Figura 3(a).

Apresenta-se na Tabela 1 a caracterização físico-química do efluente bruto 
e após a coagulação/floculação e sedimentação do efluente proveniente da lavagem de veículos.

\section{Tabela 1 - Caracterização físico-química do efluente bruto e o tratamento proposto.}

\begin{tabular}{clll}
\hline Analises & Entrada & Saída & $\begin{array}{c}\mathrm{E} \\
(\%)\end{array}$ \\
\hline $\begin{array}{c}\mathrm{pH} \\
\text { Turbidez } \\
\text { (NTU) }\end{array}$ & $7,8 \pm 0,005$ & $7,5 \pm 0,03$ & \\
$\begin{array}{c}\mathrm{DBO} 5 \\
(\mathrm{mg} / \mathrm{L})\end{array}$ & $75 \pm 3$ & $37,6 \pm 4$ & 93 \\
$\begin{array}{c}\text { Óleos } \\
(\mathrm{mg} / \mathrm{L})\end{array}$ & $65,6 \pm 5$ & $37,4 \pm 6$ & 43 \\
$\begin{array}{c}\mathrm{ST} \\
(\mathrm{mg} / \mathrm{L})\end{array}$ & $6313,3 \pm 1169$ & $504,4 \pm 33$ & 92 \\
$\begin{array}{c}\mathrm{SFT} \\
(\mathrm{mg} / \mathrm{L})\end{array}$ & $4286,7 \pm 1196$ & $304,4 \pm 24$ & 93 \\
$\begin{array}{c}\mathrm{SVT} \\
(\mathrm{mg} / \mathrm{L})\end{array}$ & $2026,7 \pm 369$ & $275,6 \pm 52$ & 86 \\
\hline
\end{tabular}

Como se pode observar na Tabela 1 , o efluente bruto já estava em conformidade com a resolução 430/11 do CONAMA no que diz respeito ao parâmetro de $\mathrm{pH}$, e após a adição do cloreto férrico ele tornou-se um pouco mais alcalino, porém continuou em conformidade com a resolução.

Obteve-se uma eficiência de $93 \%$ na redução dos sólidos em suspensão, o efluente tratado apresentou um índice de turbidez de 37,6 NTU, ficando assim em conformidade com a resolução número 430 de 2011 do CONAMA, que estabelece que o efluente para ser descartado precisa estar abaixo de 100 NTU.

Em relação à $\mathrm{DBO}_{5}$ alcançou-se apenas $32 \%$ de redução, com isso o efluente tratado permaneceu fora dos padrões exigidos, pois para se adequar seria necessária uma redução de pelo menos $60 \%$.

No que diz respeito ao teor de óleos e graxas também não se atingiu a eficiência desejada, uma vez que o resultado encontrado ficou acima do permitido pela resolução que determina que o máximo deve ser de $20 \mathrm{mg} / \mathrm{L}$. Além disso, cabe ressaltar, que o conteúdo de óleos e graxas pode ser maior do que o obtido, uma vez que a abertura do filtro utilizado no experimento de análise deste parâmetro foi maior do que o indicado na metodologia.
A resolução 430/11 do CONAMA não cita nenhum valor máximo para os sólidos totais, sólidos totais fixos e sólidos totais voláteis, contudo analisando a eficiência da remoção destes observa-se que eles apresentaram resultados elevados.

\section{Sistema Sugerido}

Procurou-se propor uma nova metodologia visando contribuir para uma redução na carga poluidora do efluente para que ele não agrida tanto o meio ambiente quando lançado em corpos de águas. Essa metodologia levou em consideração o sistema de tratamento já existente e o que foi pesquisado para o desenvolvimento deste trabalho.

Com o tratamento proposto não se obteve a eficiência desejada em termos de redução da carga poluidora para todos os parâmetros monitorados, o que pode ser observado na Tabela 1. Apesar do efluente não ter atendido as exigências para o reuso, com o tratamento proposto conseguiu-se diminuir todos os parâmetros, o que causa um menor prejuízo ao meio ambiente.

Cabe ressaltar que durante o desenvolvimento deste trabalho utilizou-se como matéria prima o efluente bruto. Caso fosse utilizado o efluente final do tratamento empregado pelas lavagens automotivas, o resultado seria uma carga poluidora ainda inferior ao obtido.

O sistema foi proposto em cima do projeto utilizado atualmente nas lavagens de veículos, sendo composto inicialmente por um gradeamento nas canaletas e antes da caixa de retenção do lodo, com a finalidade de reter sólidos maiores, seguido por uma caixa de separação água e óleo. Na sequência sugere-se que seja implantado um tanque para adição do coagulante, neste caso o cloreto férrico. Este reservatório deve ser incrementado com um misturador para promover uma maior aglutinação das partículas que não sedimentaram na caixa de retenção do lodo, e por fim uma nova caixa de sedimentação. $O$ sistema de tratamento proposto é esquematizado na Figura 4. 


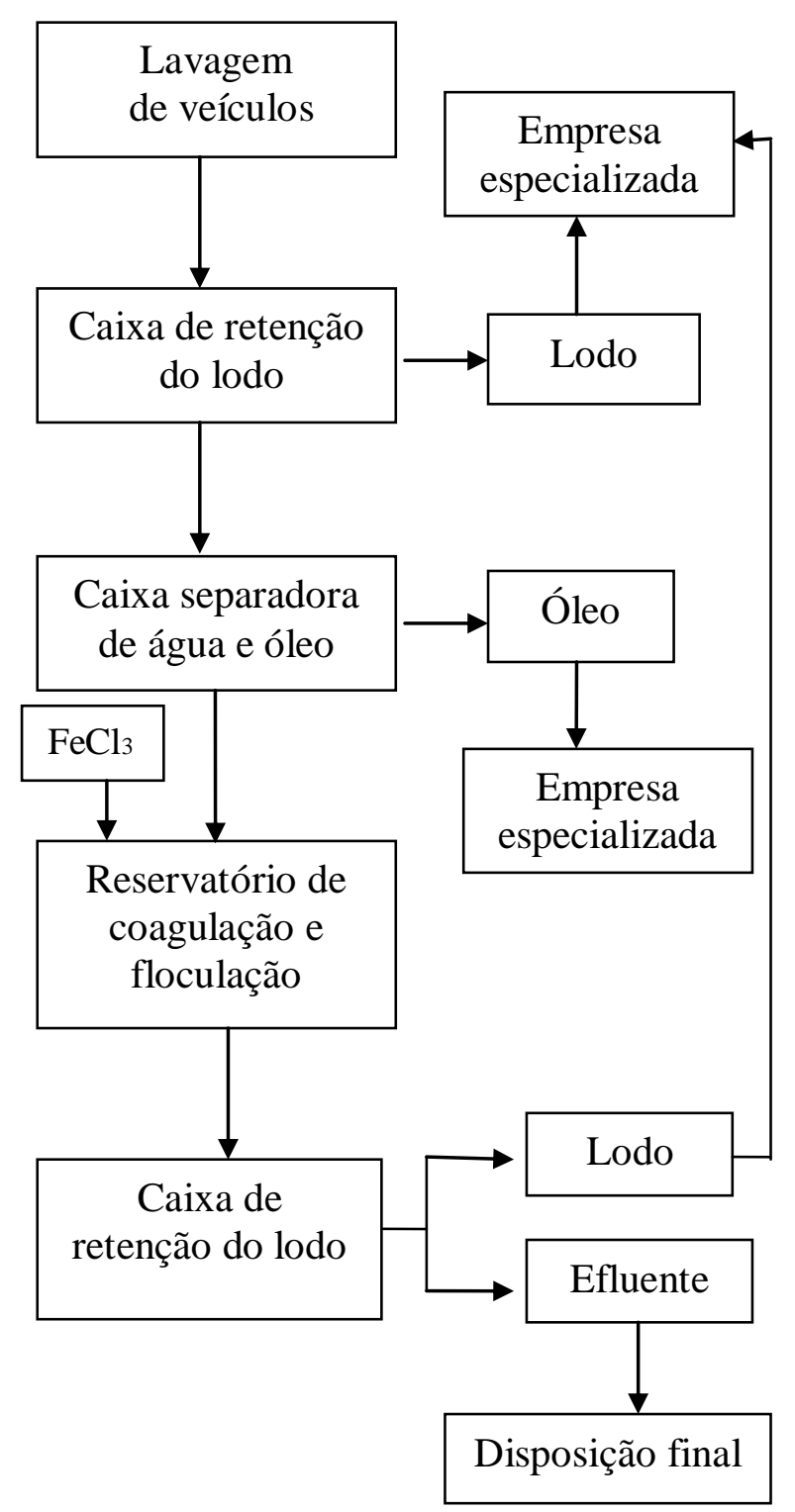

Figura 4 - Sistema proposto.

O sistema proposto pode ser considerado de baixo custo para ser implantado, além de possuir também baixo custo com reagente. Em 13 de dezembro de 2011, o cloreto férrico (500 g) foi comprado pela UNIPAMPA por $\mathrm{R} \$$ 11,32. Usando este valor como base, considerando que para cada lavagem de carro é utilizado $250 \mathrm{~L}$ de água e propondo um tratamento com $20 \mathrm{mg} / \mathrm{L}$ de cloreto férrico, o gasto com reagente seria de $\mathrm{R} \$ 0,1132$ por veículo.

\section{CONCLUSÃO}

Para o tratamento proposto neste trabalho, aplicando $20 \mathrm{mg} / \mathrm{L}$ de cloreto férrico ao efluente bruto, com 1 min de coagulação, $10 \mathrm{~min}$ de floculação e $15 \mathrm{~min}$ de sedimentação não observou-se mudanças significativas do $\mathrm{pH}$, o qual permaneceu de acordo com a norma 430/2011 do CONAMA, obteve-se uma eficiência de $93 \%$ em relação a turbidez, ficando assim em conformidade com a norma. Em relação a $\mathrm{DBO}_{5}$ alcançou-se 32 $\%$ de redução, e assim o efluente tratado permaneceu fora dos padrões exigidos. O teor de óleos e graxas também ficou acima do permitido, pois se encontrou $37,4 \pm 6,5 \mathrm{mg} / \mathrm{L}$.

O sistema proposto é composto das seguintes etapas: gradeamento nas canaletas e antes da caixa de retenção do lodo, caixa de separação água e óleo, tanque (misturador) para adição do coagulante onde irá acontecer as etapas de coagulação e floculação, e caixa de retenção de lodo. Se o tratamento proposto fosse implementado, o gasto com o reagente (cloreto férrico) ficaria em torno de $\mathrm{R} \$ 0,1132$.

\section{NOMENCLATURA}

ABNT - Associação Brasileira de Normas Técnicas.

CETESB - Companhia Ambiental do Estado de São Paulo.

CONAMA - Conselho Nacional do Meio

Ambiente.

CONSEMA - Conselho Estadual do Meio Ambiente.

DENATRAN - Departamento Nacional de Trânsito.

$\mathrm{DBO}_{5}$ - Demanda Bioquímica de Oxigênio $(\mathrm{mg} / \mathrm{L})$.

$\mathrm{E}(\%)$ - Eficiência.

$\mathrm{FeCl}_{3}$ - Clorreto Férrico

NBR - Norma Brasileira.

SFT - Sólidos Fixos Totais (mg/L).

SS - Sólidos em Suspensão (mg/L).

ST - Sólidos Totais (mg/L).

SVT - Sólidos Voláteis Totais (mg/L).

\section{REFERÊNCIAS}

CONAMA - Conselho Nacional do Meio Ambiente. Resolução $n^{\circ} 430$, de 13 de maio de 2011. Dispõe sobre as condições e padrões de lançamento de efluentes, complementa e altera a Resolução no 357, de 17 de março de 2005, do Conselho CONAMA. Diário Oficial da república federativa do Brasil, Brasília, DF, 16 de 
maio de 2011. Acessado em: http://www.mma.gov.br/port/conama/legi abre.cfm?codlegi=646

CONSEMA - Conselho Estadual Do Meio Ambiente. Resolução $\mathrm{n}^{\circ} 128$, de 24 de novembro de 2006. Dispõe sobre a fixação de Padrões de Emissão de Efluentes Líquidos para fontes de emissão que lancem seus efluentes em águas superficiais no Estado do Rio Grande do Sul. Diário Oficial da república federativa do Brasil, Brasília, DF, 24 de novembro de 2006. Acessado em: http://www.bioensaios.com.br/legisla/FEP AM\%20CONSEMA128\%20Efluentes.pdf DENATRAN - Departamento nacional de Trânsito, disponível em < http://www.denatran.gov.br/frota.htm>, acesso em 11 de setembro de 2013.

DEZOTTI, M. (2008), Processos e técnicas para o controle ambiental de efluentes líquidos. Editora E-papers, Rio de Janeiros, 360p.

PAVANELLI, G (2001), Eficiência de diferentes tipos de coagulantes na coagulação, floculação e sedimentação de água com cor ou turbidez elevada. Universidade de São Paulo, São Carlos-SP (dissertação de mestrado), 233p.

SILVA, M.O.S.A. (1997), Análises físicoquímicas para controle de estações de tratamento de esgotos. Companhia de Tecnologia de Saneamento ambiental, São Paulo-SP, 226p.

\section{AGRADECIMENTOS}

As autoras agradecem a Universidade Federal do Pampa pelo suporte recebido na realização do presente trabalho. 